Published in:

Blossfeld, H.-P., Buchholz, S., Skopek, J., Triventi, M. (Eds.). 2016. Models of Secondary Education and Social Inequality - An International Comparison.

Cheltenham, UK and Northampton, MA, USA: Edward Elgar Publishing https://www.e-elgar.com/shop/models-of-secondary-education-and-social-inequality

\title{
7. Differentiation in secondary education and inequality in educational opportunities: The case of Switzerland
}

\author{
Marlis Buchmann, Irene Kriesi, Maarten \\ Koomen, Christian Imdorf, and Ariane Basler
}

\section{INTRODUCTION}

Sociologists working in the field of education and stratification have long been concerned with how far not only ability and performance but also selection by social and migration background along with gender account for differences in young people's educational attainment. Research has recognized the complex entanglement of institutional, social, and individual characteristics that shape both educational opportunities and educational attainment. The significance of these characteristics is most visible at transitions in the educational system. In differentiated and stratified educational systems, these transitions involve placement into educational tracks with different academic requirements. For Switzerland, we examine how ability, school performance, and student social characteristics affect track placement to lower and upper secondary schooling and how allocation to secondary-level tracks determines tertiary education enrolment.

\section{THE SWISS EDUCATIONAL SYSTEM}

The Swiss educational system is highly federalist, organized at the level of 26 cantons, and known for early tracking. At both secondary and tertiary levels, it is characterized by extensive differentiation and strong stratification. We shall describe the institutional design of these two levels.

\section{Secondary Education}

Swiss secondary education is subdivided into lower and upper secondary schooling each composed of several selective tracks. Compulsory education 
ends after 9th grade with the completion of lower secondary schooling without any educational certificate being provided. This basic structure of secondary education has remained rather stable over the last 20 years.

In most cantons (20 out of 26), tracking into lower secondary education occurs after six years of primary schooling; in the others, after four or five years. All cantons have institutionalized tracks with varied academic requirements, thus grouping students by ability. However, the number as well as the organization of tracks varies between and, in many instances, within cantons. Most cantons offer two to four school types run separately; others adopt streamed courses within an integrated model or divide students into two types of core classes combined with streamed courses (CSRE 2014, 86). Five distinct types of lower secondary school tracks may be distinguished. These are the tracks with basic, intermediate, and advanced academic requirements along with a comprehensive track (still marginal to date) admitting students of all ability levels. Finally, 11 out of 26 cantons have a track called long-term baccalaureate school preparing students for advanced academic studies. The most prominent track allocation criterion in lower secondary education is school performance as indicated by grades. Teacher assessment of competencies (i.e. problem-solving capacities, social competencies) also plays a role as do teacher recommendation and parental preferences (Neuenschwander et al. 2012). Their significance differs by canton. Finally, admission to the long-term baccalaureate school depends in some cantons on the results of a formal admission test (five cantons), whereas grades, teacher recommendation, and parental preferences suffice for admission in others (six cantons).

The main institutional feature of Swiss upper secondary education is the differentiation between vocational education and training (VET) on the one side and general education on the other. VET is prominent because about 65 per cent of a birth cohort receives vocational education. VET is subdivided into company-based 'dual' programmes (apprenticeships) and school-based programmes. Most of the 230 VET programmes are company-based, combining work at a firm with one or two days per week at a vocational school. Ninety per cent of young people going into VET are channelled into company-based programmes. These programmes differ greatly in intellectual requirements and duration from two years of training of modest intellectual requirements to three- to four-year apprenticeships with medium to high requirements. Employers choose their apprentices based on their lower secondary track, grades, and their preferences for gender, nationality, age, or individual traits of the applicants. School-based VET programmes are offered for a few occupations (e.g. medical assistant, IT, design, and commerce), admitting students based on the level of lower secondary education and grades. The completion of all VET programmes is certified with a nationally 
recognized occupation-specific credential. VET programmes offer the opportunity to attain the Federal Vocational Baccalaureate granting access to tertiary-level universities of applied sciences. Admission to this supplementary track is contingent on previous academic achievement (i.e. lower and upper secondary track and grades). Upper secondary education also includes specialized schools preparing students for vocational training at the tertiary level in areas such as health, education, social work, or IT and providing a specialized baccalaureate. The main track of general education in upper secondary schooling is the baccalaureate school offered in all cantons and granting admission-free access to universities in Switzerland. Selection into this academically most demanding track varies by canton with some making it dependent on admission tests whereas others rely on the level of the lower secondary track and grades.

\section{Tertiary Education}

Tertiary education is composed of a university sector and a professional education and training (PET) sector. The former is divided into universities (governed by the cantons or the Confederation), universities of applied sciences (UAS; governed by the Confederation), and universities of teacher education (UTE; governed by the cantons). UAS are vocationally oriented, offering courses in engineering, business and economics, social sciences, health, natural sciences, and the fine arts. Access to universities requires an academic baccalaureate; access to UAS, a federal vocational or specialized baccalaureate. UAS are also open to graduates from baccalaureate schools (BS) who have gained some work experience. UTE admission criteria differ by canton. The certificate issued by UAS and UTE is the Bachelor's degree. Almost two-thirds of students pursuing higher education in the university sector enrol at a university, about one-third at a UAS, and 7 per cent at a UTE (CSRE 2014, 166). The PET sector offers both formal training at PET colleges and preparatory courses for PET and advanced PET examinations in a wide range of occupations. These provide students with the skills needed to assume technical and managerial responsibilities (e.g. to run a small or medium-sized enterprise independently or to act as experts). Access to the PET sector requires a federal VET diploma (or a baccalaureate) and work experience.

\section{STATE OF RESEARCH}

Research on inequality in secondary and tertiary education in Switzerland is not abundant. The scarce empirical evidence generally documents a strong impact of social background on children's educational attainment by international comparison (e.g. Buchmann et al. 1993; Buchmann et al. 2007). 


\section{Determinants of Secondary Track Allocation}

Research on lower secondary track allocation is limited to a few studies based on one or maximally a few cantons. In the Bernese canton, math and language grades in the last year of primary schooling have the strongest impact on track placement (Neuenschwander and Malti 2009). After controlling for grades, a strong effect of parental SES remains. Baeriswyl et al. (2006) report similar findings for the German-speaking part of the canton of Fribourg. For the agglomeration of Berne and Zurich, Beck (2014) confirms the importance of grades and parental education for track allocation. Analysing 12 cantons, Felouzis and Charmillot (2013) argue that it is less the track structure and more how tracking is organized that shapes educational inequality. Inequality stems from the cantonal differences in the proportion of students allocated to tracks of different academic requirements and in the relative significance of selection criteria. Girls are slightly overrepresented in tracks of higher academic requirements, particularly because of their better grades and higher achievement motivation (Glauser 2015). Youths with a migration background are more likely than natives to be allocated to tracks with low academic requirements although this varies greatly by migrant group (Beck 2014; Glauser 2015, 44-5). Research also points to low mobility between tracks of different academic requirements, rendering first track allocation largely irreversible (Felouzis and Charmillot 2013, 190-91).

A small minority of young people never makes the transition to upper secondary education (Buchmann 2013). Track placement in lower secondary school impacts strongly on the educational opportunities in upper secondary education (e.g. Imdorf 2005; Neuenschwander and Malti 2009; HupkaBrunner et al 2010; Falter and Wendelspiess Chavez Juarez 2011; Falter 2012; Combet 2013; Glauser 2015). These studies mostly use dichotomous definitions for upper secondary track allocation (i.e. baccalaureate school placement, vocational vs general education, company- vs school-based education), different data, and different statistical procedures. All provide evidence of the importance of social background for track allocation even after controlling for lower secondary track placement.

A shortcoming of previous research is the dichotomous conceptualization of track allocation. This contribution fills this gap by using a more refined concept of upper secondary tracking that distinguishes VET programmes with low and high academic requirements, specialized schools, and baccalaureate schools. Studies assessing primary and secondary effects of social background on track allocation are still scarce. Using different decomposition and operationalization methods, Combet (2013) showed that youths of well-educated or service class families have significantly higher chances of attending baccalaureate schools. The primary effect amounts to 
approximately 20 per cent. Gender also affects allocation to upper secondary education with women being more likely to enter school-based programmes (Hupka-Brunner et al. 2010). Youths with a migration background, particularly those born abroad, encounter more difficulties in entering company-based vocational training (Imdorf 2005).

\section{Determinants of Tertiary Track Allocation}

Social background effects on higher education enrolment are strong (Buchmann et al. 2007; Denzler 2011) with social inequalities being stronger in access to universities compared to universities of applied sciences (UAS), teacher education (UTE), and professional education and training (PET) (Denzler 2011). Empirical evidence on access to different sectors of tertiary education as a function of upper secondary tracking and social origin is still scarce. One finding is that people born around 1960 were unlikely to enter higher vocational education with a baccalaureate although this track was accessible to them (Buchmann et al. 2007). Findings on tertiary education aspirations among more recent baccalaureate school graduates show higher aspirations for university studies among high SES students whereas lower SES students aspire more often to UAS and UTE (Denzler 2011). Lower SES vocational baccalaureate holders access higher education less often compared to higher SES holders, even though the former more often obtain a federal vocational baccalaureate than an academic baccalaureate (Schumann 2011). Falter and Wendelspiess Chavez Juarez (2016) confirm that the federal vocational baccalaureate reinforces social inequalities among VET graduates. Furthermore, reading literacy skills in 9th grade remain predictive for transitions from academic and vocational upper secondary tracks to tertiary education (Schumann 2011).

Samuel et al. (2014) have analysed long-term effects of lower secondary attainment and shown that social background and performance determine selection into upper secondary tracks. This track effect predicts further educational outcomes. Extending previous analyses, this contribution uses multifaceted track distinctions on both the upper secondary and tertiary level to analyse how allocation to secondary level tracks determines long-term educational outcomes. Whereas gender differences in access to the PET sector have disappeared, women prefer access to universities and men choose UAS slightly more frequently (Hupka-Brunner et al. 2011; CSRE 2014).

\section{DATA AND METHODS}

The transitions to lower and upper secondary education are based on the Swiss Survey of Children and Youth COCON (www.cocon.uzh.ch). This 
longitudinal multi-informant study, representative for the German- and French-speaking parts of Switzerland, includes a birth cohort of children born 1999/2000 and a youth cohort born 1990/1991. Data was collected between 2006 and 2013 when the children were six, seven, nine, 12, and 13 years old and the youths $15,16,18$, and 21 years old.

Lower secondary track allocation is examined with the child cohort $(N=$ $1273)$; upper secondary allocation, with the youth cohort $(N=1258)$. Cases with insufficient longitudinal information ( 25 per cent in the child and 13 per cent in the youth cohort) were not included in the analysis. Those never making the transition of interest (1.6 per cent in both cohorts), entering school abroad (4 per cent in the youth cohort), or making the transition to upper secondary school before the age of 15 (10.8 per cent $)^{1}$ were also excluded.

First track allocation in lower secondary education distinguishes between tracks with low and high academic requirements and a comprehensive track. Allocation in upper secondary education differentiates VET with low or medium intellectual requirements (Levels 1-4 based on Stalder 2011, labelled VET-) from VET with high requirements (Levels 5-6, labelled VET+), specialized schools (SS), and baccalaureate schools (BS). SES is measured with highest parental education $(0=$ max. upper secondary; $1=$ tertiary). ${ }^{2} Z$-standardized indicators capture grades in the local language and in math and basic cognitive abilities measured at the end of primary or lower secondary school for track allocation to lower and upper secondary education respectively. A migration background is coded for children whose mother tongue is not the local language. Gender is coded 0 for women ( 1 for men). In the upper secondary model, we also include the cantonal proportion of baccalaureates (2009) and entry regulations for baccalaureate schools $(1=$ entry exam). ${ }^{3}$

The transition to tertiary education is based on the Transitions from Education to Employment (TREE) survey, a nationally representative Swiss PISA 2000 school-leaver cohort study. Annual surveys ran from 2001 to 2007 with an eighth wave in 2010 (TREE 2013). We use data from 3424 respondents.

Transition from upper secondary to tertiary education is coded as first enrolment in tertiary education programmes, distinguishing between universities, UAS/UTE, and PET. Independent variables are coded in accordance with COCON, exceptions being lower secondary education that has a binary coding $(1=$ track with high academic requirements, $0=$ comprehensive and low tracks). At the upper secondary level, specialized schools (SS) are merged with VET+. PISA 2000 reading scores measure ability. We also include a variable for educational aspirations at the end of 9 th grade $(1=$ higher education $)$. 
To assess the effects of social characteristics and ability on lower and upper secondary track allocation and tertiary enrolment, we estimated multinomial regression models (based on weighted data). The KHB method (Karlson and Holm 2011) was applied to decompose primary and secondary effects of social background. Models are estimated jointly for boys and girls because there are no gender differences.

\section{RESULTS}

\section{Lower Secondary Track Allocation}

Descriptive analyses have shown that after primary school, one-third of children (32.1 per cent) enter a lower secondary school track with low academic requirements. A minority of 16.2 per cent attend a comprehensive track, and just over one-half (51.8 per cent) enter a track with high requirements. Boys are slightly overrepresented in the low requirement; girls, in the high requirement tracks.

High SES children have significantly higher odds of entering the comprehensive track or one with high academic requirements than one with low requirements (Table 7.1). Coefficients become slightly smaller after controlling for ability, but remain significant. High SES children's average probability of entering a high requirement track is 16 percentage points higher compared to that of lower SES children.

Ability shows by far the strongest effects on lower secondary track allocation. Once grades (language, math) and cognitive ability are controlled, the pseudo $R^{2}$ rises from 2 per cent to 16 per cent. The probability of entering a high-requirement or comprehensive track rises with increasing language and math grades. Cognitive abilities are irrelevant for track allocation once grades are considered. Beyond grades and abilities, gender and migration background do not matter for lower secondary track placement. We conclude that lower secondary track allocation depends primarily on SES and grades in primary school.

To assess the extent to which the SES effect on track allocation is direct or mediated by ability, we decompose our results using the KBH method. The confounding percentage coefficients (Table 7.1) reveal that direct (secondary) effects dominate the allocation process. Irrespective of ability, track allocation depends strongly on parental SES. Only 38 per cent (comprehensive track) and 35 per cent (high requirement track) of the SES effect is mediated by ability (primary effect). The components of difference show that, with about 20 per cent, math grades in primary school contribute 
Table 7.1: Multinomial regression models predicting entry into lower secondary education (low track as reference category, results as odds ratios [a] and average marginal effects $[\mathrm{b}], N=908$ )

\begin{tabular}{|c|c|c|c|c|c|c|c|}
\hline & M1a & M1b & $\mathrm{M} 2 \mathrm{a}$ & M2b & M3a & M3b & Conf. $\%{ }^{\mathrm{a}}$ \\
\hline \multicolumn{8}{|c|}{ Comprehensive track } \\
\hline SES & $2.24 *$ & 0.00 & $2.15+$ & 0.00 & $2.16+$ & 0.00 & \\
\hline Grade local language & & & $2.23 * *$ & 0.03 & $2.26^{* *}$ & $0.03+$ & 16.61 \\
\hline Grade math & & & $1.76^{* *}$ & 0.00 & $1.78^{* *}$ & 0.00 & 20.53 \\
\hline Basic cognitive abilities & & & 1.07 & 0.00 & 1.07 & 0.00 & 1.34 \\
\hline Migration background & & & & & 0.93 & -0.01 & \\
\hline Male & 0.74 & -0.02 & 0.78 & -0.02 & 0.77 & -0.02 & \\
\hline Constant & $0.55^{* *}$ & & 0.58 & & 0.93 & & \\
\hline \multirow[t]{2}{*}{ Total confounding $\%$} & & & & & & & 38.48 \\
\hline & \multicolumn{6}{|c|}{ High track } & \\
\hline SES & $3.50 * *$ & $0.24 * *$ & $3.12 * *$ & $0.16^{* *}$ & $3.12^{* *}$ & $0.16^{* *}$ & \\
\hline Grade local language & & & $2.34 * *$ & $0.10^{* *}$ & $2.36^{* *}$ & $0.10 * *$ & 12.56 \\
\hline Grade math & & & $2.22 * *$ & $0.11^{* *}$ & $2.23^{* *}$ & $0.11 * *$ & 20.59 \\
\hline Basic cognitive abilities & & & 1.12 & 0.02 & 1.12 & 0.02 & 1.75 \\
\hline Migration background & & & & & 1.02 & 0.01 & \\
\hline Male & 0.82 & -0.02 & 0.83 & -0.02 & 0.82 & -0.02 & \\
\hline Constant & $1.54^{*}$ & & $2.36^{* *}$ & & $2.43 *$ & & \\
\hline Total confounding $\%$ & & & & & & & 34.80 \\
\hline$\overline{\text { Pseudo } R^{2}}$ & & & & & & & \\
\hline
\end{tabular}

Source: Own calculations based on weighted COCON data

Notes: $\quad+p<0.10, * p<0.05, * * p<0.01 . \mathrm{M}=$ model. ${ }^{\mathrm{a}}$ Confounding percentage based on KHB decomposition; confounding ratio: comprehensive $=1.63$, high level $=1.53$. 
most to the indirect effect. This is followed by language grades. The contribution of cognitive abilities is negligible (less than 2 per cent).

\section{Upper Secondary Track Allocation}

A total of 41.5 per cent of all adolescents in our sample have entered VET(low/medium requirements); 22.5 per cent, VET+ (high requirements); 8 per cent, an upper secondary specialized school (SS); and 26.3 per cent, a baccalaureate school (BS). Track change after first entry into upper secondary school is infrequent. Only 2 per cent of VET entrants later change into SS or BS. Of those first entering SS, 4 per cent transfer to BS and 18 per cent to VET. Of those starting off in BS, 3 per cent transfer to SS and 10 per cent to VET. Only 1.6 per cent of the sample has never entered upper secondary education by the age of 21 with low requirement lower secondary track attendees, migration background youths, and girls being overrepresented. Girls are also overrepresented in SS and BS; boys, in both types of VET.

The multinomial regression estimates (Table 7.2) reveal that adolescents' SES impacts only weakly on the probability of entering VET+ compared to the reference group VET-. However, high SES adolescents have significantly higher odds of entering SS or BS than choosing VET-. After controlling for lower secondary tracking and performance, the SES effect decreases, but remains large and significant. On average, the probability that children from high SES families will enter VET + is even 6 percentage points lower compared to their counterparts from low SES families. The average probability of entering a SS is 4 percentage points higher; that of entering a BS even 9 percentage points higher (see average marginal effects in Table 7.2).

Lower secondary track allocation matters greatly for upper secondary education, increasing the pseudo $R^{2}$ by 9 percentage points. Adolescents from comprehensive and high requirement tracks have a significantly higher probability of entering VET+ or SS compared to those from low requirement tracks. The odds of entering BS are about 20 times higher for those from high requirement tracks. Comprehensive lower secondary track attendees have, on average, a 17 percentage point higher probability of entering VET+ compared to those from low requirement tracks (see average marginal effects). Their average probability of entering SS is 7 percentage points higher. Having attended a lower secondary track with high requirements, adolescents' average probability of entering an SS is about 5 percentage points higher, and the average probability of entering a BS even 28 percentage points higher. 
Table 7.2: Multinomial regression models predicting entry into upper secondary education (VET- as reference category, results as odds ratios [a] and average marginal effects [b], $N=891$ )

\begin{tabular}{|c|c|c|c|c|c|c|c|c|c|c|c|}
\hline & M1a & M1b & M2a & $\mathrm{M} 2 \mathrm{~b}$ & M3a & M3b & M4a & M4b & M5a & M5b & Conf. $\%{ }^{\mathrm{a}}$ \\
\hline \multicolumn{12}{|c|}{ VET+ } \\
\hline SES & 1.29 & -0.03 & 1.09 & -0.04 & 0.95 & -0.06 & 0.91 & $-0.07+$ & 0.95 & $-0.06+$ & \\
\hline \multicolumn{12}{|l|}{ Lower secondary track (ref. Low) } \\
\hline Comprehensive & & & $2.71 * *$ & $0.18^{* *}$ & $2.59 * *$ & $0.17 * *$ & $2.59 * *$ & $0.16^{* *}$ & $2.72 * *$ & $0.17 * *$ & 13.81 \\
\hline High & & & $3.02 * *$ & 0.04 & $2.90 * *$ & 0.02 & $2.65^{* *}$ & 0.02 & $2.69 * *$ & 0.02 & 69.30 \\
\hline Grade local language & & & & & 0.94 & -0.03 & 0.96 & -0.02 & 0.96 & -0.02 & -3.25 \\
\hline Grade math & & & & & $1.30^{* *}$ & $0.03 *$ & $1.31 * *$ & $0.03 *$ & $1.31 * *$ & $0.03 *$ & 33.78 \\
\hline Basic cognitive abilities & & & & & $1.38^{* *}$ & $0.03 *$ & $1.35^{* *}$ & $0.04 *$ & $1.49 * *$ & $0.03 *$ & 37.26 \\
\hline Basic cognitive abilities $\times$ SES & & & & & & & & & $0.56+$ & $-0.06+$ & \\
\hline Baccalaureate ratio & & & & & & & 1.16 & -0.03 & 1.18 & -0.03 & \\
\hline Baccalaureate entry exam & & & & & & & 1.18 & $0.07+$ & 1.17 & $0.07+$ & \\
\hline Migration background & & & & & & & $0.54 *$ & $-0.13 * *$ & $0.55^{*}$ & $-0.13 * *$ & \\
\hline Male & 1.02 & 0.05 & 1.06 & 0.05 & 0.98 & 0.04 & 1.01 & 0.03 & 1.02 & 0.04 & \\
\hline Constant & $0.51^{* *}$ & & $0.28 * *$ & & $0.31^{* *}$ & & $0.34 * *$ & & $0.34 * *$ & & \\
\hline \multirow[t]{2}{*}{ Total confounding $\%$} & & & & & & & & & & & 150.90 \\
\hline & \multicolumn{10}{|c|}{ Specialized schools (SS) } & \\
\hline SES & $2.61 * *$ & $0.05^{*}$ & $2.16^{*}$ & $0.04+$ & $1.95+$ & $0.04+$ & $2.28 *$ & $0.04+$ & $2.27 *$ & 0.04 & \\
\hline Lower secondary track & & & & & & & & & & & \\
\hline Comprehensive & & & $2.83 *$ & 0.05 & $2.69^{*}$ & 0.05 & $3.42 * *$ & $0.07 *$ & $3.51 * *$ & $0.07 *$ & 2.73 \\
\hline High & & & $5.42 * *$ & $0.05^{*}$ & $5.04 * *$ & $0.05+$ & $7.00 * *$ & $0.05 *$ & $7.05^{* *}$ & $0.05^{*}$ & 21.16 \\
\hline Grade local language & & & & & 1.15 & 0.01 & 1.29 & 0.01 & 1.30 & 0.01 & 2.98 \\
\hline Grade math & & & & & 1.04 & -0.01 & 1.10 & -0.01 & 1.10 & -0.01 & 1.73 \\
\hline Basic cognitive abilities & & & & & 1.36 & 0.01 & 1.27 & 0.00 & 1.32 & 0.00 & 4.55 \\
\hline Basic cognitive abilities $\times$ SES & & & & & & & & & 0.78 & 0.05 & \\
\hline
\end{tabular}


Table 7.2: Continued

\begin{tabular}{|c|c|c|c|c|c|c|c|c|c|c|c|}
\hline & M1a & M1b & M2a & $\mathrm{M} 2 \mathrm{~b}$ & M3a & M3b & M4a & M4b & M5a & M5b & Conf. $\%{ }^{a}$ \\
\hline Baccalaureate ratio & & & & & & & $2.34 * *$ & $0.04 *$ & $2.37 * *$ & $0.04 *$ & \\
\hline Baccalaureate entry exam & & & & & & & 0.71 & 0.00 & 0.72 & 0.00 & \\
\hline Migration background & & & & & & & $2.34 *$ & $0.07 * *$ & $2.37 *$ & $0.07 * *$ & \\
\hline Male & $0.32 * *$ & $-0.08 * *$ & $0.34 * *$ & $-0.08 * *$ & $0.35 * *$ & $-0.07 * *$ & $0.34 * *$ & $-0.07 * *$ & $0.35 * *$ & $-0.07 * *$ & \\
\hline Constant & $0.24 * *$ & & $0.10 * *$ & & $0.11 * *$ & & $0.09 * *$ & & $0.09 * *$ & & \\
\hline \multirow[t]{2}{*}{ Total confounding $\%$} & & & & & & & & & & & 33.15 \\
\hline & \multicolumn{10}{|c|}{ Baccalaureate schools (BS) } & \\
\hline$\overline{\text { SES }}$ & $3.27 * *$ & $0.15 * *$ & $2.61 * *$ & $0.10^{* *}$ & $2.25 * *$ & $0.08 * *$ & $2.69 * *$ & $0.08 * *$ & $2.92 * *$ & $0.09 * *$ & \\
\hline \multicolumn{12}{|c|}{ 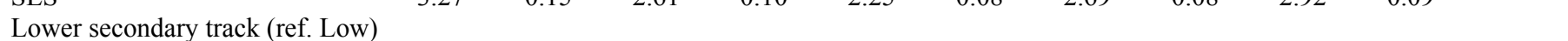 } \\
\hline Comprehensive & & & 0.93 & -0.03 & 0.88 & -0.03 & 0.92 & -0.03 & 0.93 & -0.04 & -0.15 \\
\hline High & & & $15.20 * *$ & $0.32 * *$ & $15.44^{* *}$ & $0.31 * *$ & $19.73 * *$ & $0.28 * *$ & $19.94 * *$ & $0.28^{* *}$ & 24.52 \\
\hline Grade local language & & & & & $1.33^{*}$ & $0.03 *$ & $1.45^{*}$ & $0.03 *$ & $1.45^{*}$ & $0.03 *$ & 3.27 \\
\hline Grade math & & & & & 1.49 & $0.03 *$ & $1.62 * *$ & $0.04 * *$ & $1.62 * *$ & $0.04 * *$ & 6.93 \\
\hline Basic cognitive abilities & & & & & $1.46^{* *}$ & 0.02 & $1.40^{*}$ & 0.02 & $1.62 * *$ & 0.02 & 4.78 \\
\hline Basic cognitive abilities $\times$ SES & & & & & & & & & $0.56^{*}$ & $0.09 * *$ & \\
\hline Baccalaureate ratio & & & & & & & $3.00 * *$ & $0.08 * *$ & $3.04 * *$ & $0.08 * *$ & \\
\hline Baccalaureate entry exam & & & & & & & $0.33 * *$ & $-0.11 * *$ & $0.32 * *$ & $-0.11 * *$ & \\
\hline Migration background & & & & & & & 1.35 & 0.03 & 1.39 & 0.03 & \\
\hline Male & $0.64 *$ & -0.05 & $0.66+$ & -0.03 & 0.67 & -0.02 & 0.72 & -0.01 & 0.73 & -0.01 & \\
\hline Constant & $0.38^{* *}$ & & $0.10^{* *}$ & & $0.09 * *$ & & $0.09^{* *}$ & & $0.09^{* *}$ & & \\
\hline Total confounding $\%$ & & & & & & & & & & & 39.35 \\
\hline
\end{tabular}

\begin{tabular}{llllll} 
Total confounding \% & \multicolumn{2}{c}{0.12} & 39.35 \\
\hline Pseudo $R^{2}$ & 0.03 & 0.12 & 0.15 & 0.21 & 0.22
\end{tabular}

Source: Own calculations based on weighted COCON data.

Notes: $\quad+p<0.10,{ }^{*} p<0.05,{ }^{* *} p<0.01 . \mathrm{M}=$ model. ${ }^{\mathrm{a}}$ Confounding percentage based on KHB decomposition; confounding ratio: $\mathrm{VET}+=-1.96, \mathrm{SS}=1.50$, $\mathrm{BS}=1.65$. 
Turning to ability, access to upper secondary specialized schools (SS) depends neither on language and math grades nor on cognitive ability. High local language grades increase the odds of entering BS by 1.5. High math grades and high levels of cognitive ability increase the probability of entering VET + and BS compared to VET-. The positive effect of cognitive ability holds mainly for lower SES youths (see interaction effect in Table 7.2). Cognitive ability plays a significantly less important role in explaining access to VET+ and BS for high SES children.

As expected, the chance of entering a baccalaureate school (BS) increases significantly the higher the cantonal proportion of baccalaureate degrees and thus the proportion of places in BS. ${ }^{4}$ It decreases in cantons with entry exams that curb access to BS. Gender matters only for access to SS. Boys have significantly lower odds of entering this track. Migration background lowers the probability of entering VET + but increases that of entering SS compared to the reference group. A likely cause is discrimination in firmbased VET in which ascribed characteristics matter for access.

We conclude that the 'dividing line' between VET+ and VET- is lower secondary track allocation, math grades, cognitive ability, and migration background. Young people entering a SS differ from the reference group VET- through their more favourable socio-economic background and lower secondary track allocation. They do not differ in ability. High-ability children have high odds of entering a BS, particularly those from high SES families and a lower secondary track with high requirements.

Turning to the decomposition findings in Table 7.2, the comparison of VET + and VET- reveals a confounding ratio of minus two and a confounding percentage of 151. Indirect SES effects thus dominate. The slight (nonsignificant) overrepresentation of high SES pupils in VET+ shown in Model 1a is due mainly to lower secondary track allocation and ability. Controlling for ability results in a slight positive discrimination of low SES pupils.

For special schools (SS) and baccalaureate schools (BS), direct SES effects play a much larger role. Only 33 per cent (SS) and 39 per cent (BS) of the total SES effect is mediated by tracking and ability, whereas 67 per cent and 61 per cent respectively are due to direct SES effects. The coefficients on confounding further show that 21 per cent (SS) and 25 per cent (BS) of the total effects are mediated by the influence of SES on lower secondary track placement. The contribution of ability measures to the mediating effect sum up to 9 per cent (SS) and 15 per cent (BS) respectively.

\section{Tertiary Education Enrolment}

A total of 77 per cent of the TREE cohort enrolled in upper secondary education did not enter tertiary education within ten years after leaving lower 
secondary education. Seventeen per cent continued their education in a university programme, of whom 7 per cent attended a university of applied sciences or teacher education (UAS/UTE), and 7 per cent enrolled in professional education and training (PET). High SES individuals are overrepresented in all three types of tertiary education and women are overrepresented among university entrants.

First, upper secondary and tertiary enrolment are strongly related: 64 per cent of students graduating from baccalaureate schools (BS) enrolled at university, 15 per cent at UAS/UTE, and 19 per cent did not start tertiary education. Eleven per cent of VET + students without a vocational baccalaureate entered PET and 84 per cent remained without tertiary education. In contrast, those 20 per cent of VET+ students with a vocational baccalaureate show fairly high tertiary enrolment rates with 32 per cent of them entering UAS/UTE and 14 per cent entering PET. Only few VETstudents ( 5 per cent) obtained a vocational baccalaureate and the majority remained without tertiary education ( 95 per cent).

The multinomial regression estimates of enrolment in universities, UAS/UTE, or PET (with no tertiary education being the reference group) reveal that SES significantly affects access to each tertiary sector (Table 7.3). The average marginal effects in the first model indicate that high SES youth have a 10 percentage point higher probability of entering a university and a 4 to 5 percentage point higher probability of entering UAS/UTE or PET respectively. Men have a 6 percentage point lower probability of accessing a university compared to women.

Students from a lower secondary track with high requirements show a 12 percentage point higher probability of entering university and an 8 percentage point higher probability of entering UAS/UTE (Model 2). Lower secondary tracking does not predict PET entry. Reading skills and math grades affect enrolment in universities and UAS/UTE (reading skills for university entry especially). Local language grade matters for entering UAS/UTE and PET, but not university (controlling for reading skills).

Accounting for upper secondary tracking in Model 3, the pseudo $R^{2}$ doubles to 30 per cent, mostly attributable to the strong effect of baccalaureate school (BS) enrolment indicating a 36 percentage point higher probability of entering university. Consequently, the average marginal effect of lower secondary track drops from 12 to 5 percentage points while remaining statistically significant. BS enrolment does not predict entry into universities of applied sciences and teacher education (UAS/UTE) and correlates negatively with entry into professional education and training (PET). The VET programmes' academic requirement levels are more predictive for enrolment in UAS/UTE, with VET- students accessing UAS/UTE less frequently compared to VET+ students. These levels make no 
Table 7.3: Multinomial regression models predicting entry into tertiary education (no tertiary enrolment as reference category, results as odds ratios [a] and average marginal effects [b], $N=2832$ )

\begin{tabular}{|c|c|c|c|c|c|c|c|}
\hline & M1a & M1b & M2a & M2b & M3a & M3b & Conf. $\%^{\mathrm{a}}$ \\
\hline \multicolumn{8}{|c|}{ University } \\
\hline SES & $3.20 * *$ & $0.10 * *$ & $3.03 * *$ & $0.08 * *$ & $3.28 * *$ & $0.05^{* *}$ & \\
\hline Male & $0.50 * *$ & $-0.06^{* *}$ & 0.79 & -0.02 & $1.66+$ & $0.02+$ & \\
\hline Reading skills & & & $6.26^{* *}$ & $0.12 * *$ & $3.22 * *$ & $0.05^{* *}$ & 16.67 \\
\hline Math grades & & & $2.44^{* *}$ & $0.06^{* *}$ & $2.41^{* *}$ & $0.04 *$ & -2.33 \\
\hline Language grades & & & 1.42 & 0.01 & 1.37 & 0.01 & 1.95 \\
\hline Lower secondary track: High (ref. Low) & & & $13.77 * *$ & $0.12 * *$ & $3.63^{*}$ & $0.05^{*}$ & 22.90 \\
\hline Upper secondary: BS & & & & & $66.65 * *$ & $0.36^{* *}$ & 57.23 \\
\hline Upper secondary: VET- & & & & & 0.88 & 0.00 & 3.58 \\
\hline Educational aspirations & & & & & 2.37 & 0.02 & \\
\hline Migration background & & & & & 1.41 & $0.06+$ & \\
\hline Constant & $0.12 * *$ & & $0.00 * *$ & & $0.00 * *$ & & \\
\hline \multirow[t]{2}{*}{ Total confounding $\%$} & & & & & & & 27.03 \\
\hline & \multicolumn{6}{|c|}{ UAS/UTE } & \\
\hline SES & $2.18^{* *}$ & $0.04 * *$ & $2.02 * *$ & $0.02+$ & $1.87 * *$ & 0.02 & \\
\hline Male & $0.66^{*}$ & -0.02 & 1.01 & 0.01 & 1.27 & 0.01 & \\
\hline Reading skills & & & $2.81 * *$ & $0.04 * *$ & $1.99 *$ & 0.02 & 11.84 \\
\hline Math grades & & & $2.10 * *$ & $0.03 *$ & $1.92 *$ & $0.02 *$ & -2.10 \\
\hline Language grades & & & $1.99^{*}$ & $0.03 *$ & $1.85^{*}$ & $0.03 *$ & 4.62 \\
\hline Lower secondary track: High (ref. Low) & & & $9.53^{* *}$ & $0.08^{*}$ & $5.19 * *$ & $0.06^{* *}$ & 35.44 \\
\hline Upper secondary: BS & & & & & $2.94 * *$ & 0.02 & 17.79 \\
\hline Upper secondary: VET- & & & & & $0.40 * *$ & $-0.04 * *$ & 32.40 \\
\hline
\end{tabular}


Table 7.3: Continued

\begin{tabular}{|c|c|c|c|c|c|c|c|}
\hline & M1a & M1b & $\mathrm{M} 2 \mathrm{a}$ & $\mathrm{M} 2 \mathrm{~b}$ & M3a & M3b & Conf. $\%{ }^{\mathrm{a}}$ \\
\hline Educational aspirations & & & & & 1.27 & 0.01 & \\
\hline Migration background & & & & & 0.57 & $-0.04 *$ & \\
\hline Constant & $0.09 * *$ & & $0.00 * *$ & & $0.00 * *$ & & \\
\hline \multirow[t]{2}{*}{ Total confounding $\%$} & & & & & & & 36.69 \\
\hline & \multicolumn{6}{|c|}{ PET } & \\
\hline SES & $2.70 * *$ & $0.05 *$ & $2.58^{* *}$ & $0.04 *$ & $2.42 * *$ & $0.05 *$ & \\
\hline Male & 0.70 & -0.01 & 0.88 & -0.01 & 0.86 & -0.01 & \\
\hline Reading skills & & & $1.74+$ & 0.01 & $1.64+$ & 0.02 & 28.29 \\
\hline Math grades & & & 1.50 & 0.01 & 1.45 & 0.01 & -3.93 \\
\hline Language grades & & & $2.33^{* *}$ & $0.04 *$ & $2.26^{*}$ & $0.04 * *$ & 20.19 \\
\hline Lower secondary track: High (ref. Low) & & & 1.67 & 0.01 & 1.43 & $0.01 *$ & 25.59 \\
\hline Upper secondary: BS & & & & & 0.57 & $-0.07 * *$ & -30.30 \\
\hline Upper secondary: VET- & & & & & $0.60+$ & -0.03 & 60.15 \\
\hline Educational aspirations & & & & & 0.85 & -0.01 & \\
\hline Migration background & & & & & 0.73 & -0.02 & \\
\hline Constant & $0.07 * *$ & & $0.01 * *$ & & $0.02 * *$ & & \\
\hline Total confounding $\%$ & & & & & & & 11.11 \\
\hline Pseudo $R^{2}$ & & & & & & & \\
\hline
\end{tabular}

Source: Own calculations based on weighted TREE data.

Notes: $+p<0.10, * p<0.05, * * p<0.01$. $\mathrm{M}=$ model. ${ }^{a}$ Confounding percentage based on KHB decomposition, confounding ratio: university $=-1.37$, $\mathrm{UAS} / \mathrm{UTE}=1.58, \mathrm{PE} \mathrm{T}=1.12$. 
difference for enrolment in PET. Findings remain robust after controlling for educational aspirations prior to upper secondary track allocation and migration background. The latter negatively impacts access to UAS/UTE.

Lower and upper secondary school variables do not reduce the SES effect on PET entry. Decomposition analysis indicates that 89 per cent of the (moderate) SES effect on PET entry is due to secondary effects. In contrast, the SES effects on enrolment in university and UAS/UTE are gradually reduced once lower and upper secondary tracking are taken into account. In the final model, educational variables account for 27 per cent of the SES effect on university access and 37 per cent of the SES effect on UAS/UTE access. For universities, BS enrolment followed by reading skills mediate the SES effect. In the case of UAS/UTE, lower secondary tracking and within VET tracking mediate most of the SES effect.

We conclude that overall SES effects on tertiary education entry in Switzerland are moderate, especially on entry into UAS/UTE and PET, and mainly of a secondary nature. Our results underline the binary divide of the tightly linked upper secondary and tertiary education with only little permeability between the general and the vocational tracks. However, VET+ programmes giving access to the vocational baccalaureate open up the route to UAS/UTE.

\section{CONCLUSIONS}

Our findings provide strong evidence that in the highly differentiated and strongly stratified Swiss educational system, track allocation to lower secondary schooling, taking place around the age of 12 , sets the course for future educational opportunities. It greatly predicts selection into upper secondary educational tracks, enabling or foreclosing, in turn, access to tertiary-level education. Opportunities to pursue tertiary education are thus determined almost completely at the level of secondary schooling. Even when controlling for ability and performance, social background exerts a significant effect on tracking at the secondary level. Once secondary-level tracking is controlled, the SES effect on tertiary enrolment weakens considerably. The observed social inequalities in educational opportunities are thus most prevalent at the level of secondary education and decline thereafter. These findings suggest that educational policy measures should focus on reducing social inequalities in educational opportunities at the level of secondary schooling by making track allocation more dependent on meritocratic criteria.

The differentiation between VET programmes with higher and lower academic requirements delivered evidence indicating that it is not only the 
'divide' between general and vocational education that shapes educational opportunities in Switzerland. Academically more demanding VET programmes do indeed provide access to particular strands of tertiary education. Given the lasting importance of lower secondary track allocation for inequalities in educational opportunities, future research could investigate further the immense complexity of this part of the educational system characterized by variation not only between but also within cantons.

\section{NOTES}

1 For these cases, we lack information on ability measured before the transition.

2 The lower category includes vocational tertiary education (ISCED 5B) building on upper secondary education and often not requiring formal schooling.

3 Controls capturing grade repetition, age at entry into upper secondary education, and transition duration were excluded from the final models because they failed to attain statistical significance.

4 The significant effect for entry into SS implies that large cantonal shares of baccalaureate degrees and general middle school degrees go hand in hand.

\section{REFERENCES}

Baeriswyl, F., C. Wandeler, U. Trautwein and K. Oswald (2006), 'Leistungstests, Offenheit von Bildungsgängen und obligatorische Beratung der Eltern', Zeitschrift für Erziehungswissenschaft, 9, 373-92.

Beck, M. (2014), Bildungserfolg von Migranten: Der Beitrag der Rational-ChoiceTheorien bei der Erklärung von migrationsbedingten Bildungsungleichheiten in Bern und Zürich, Bern, Switzerland: Haupt.

Buchmann, M. (2013), 'Bildungsungleichheiten als gesellschaftliche Herausforderung in der Schweiz', in R. Becker, P. Bühler and T. Bühler (eds), Bildungsungleichheit und Gerechtigkeit: Wissenschaftliche und gesellschaftliche Herausforderungen, Bern, Switzerland: Haupt, pp. 53-70.

Buchmann, M., M. Charles and S. Sacchi (1993), 'The lifelong shadow: Social origins and educational opportunities in Switzerland', in Y. Shavit and H.-P. Blossfeld (eds), Persistent Inequalities. Changing Educational Stratification in Thirteen Countries, Boulder, CO: West View Press, pp. 177-92.

Buchmann, M., S. Sacchi, M. Lamprecht and H. Stamm (2007), 'Tertiary education expansion and social inequality in Switzerland', in Y. Shavit, R. Arum, A. Gamoran and G. Menahem (eds), Expansion, Differentiation and Stratification in Higher Education: A Comparative Study, Stanford, CA: Stanford University Press, pp. $321-48$.

Combet, B. (2013), 'Zum Einfluss von primären und sekundären Effekten der sozialen Herkunft beim zweiten schulischen Übergang in der Schweiz. Ein Vergleich unterschiedlicher Dekompositions- und Operationalisierungsmethoden', Schweizerische Zeitschrift für Soziologie, 35 (3), 447-71. 
CSRE (ed.) (2014), Swiss Education Report 2014, Aarau, Switzerland: Swiss Coordination Centre for Research in Education.

Denzler, S. (2011), 'University or polytechnic? Family background effects on the choice of higher education institution', Swiss Journal of Sociology, 37 (1), 79-97.

Falter, J.-M. (2012), 'Parental background, upper secondary transition and schooling inequality in Switzerland', Swiss Journal of Sociology, 38 (2), 201-22.

Falter, J.-M. and F. Wendelspiess Chavez Juarez (2011), 'Does tracking shape intergenerational transmission of educational attainment? Evidence from Switzerland', Labor: Human Capital eJournal, 10, 1-15.

Falter, J.-M. and F. Wendelspiess Chavez Juarez (2016), 'Professional baccalaureate as inequality reducing measure?', in K. Scharenberg, S. Hupka-Brunner, T. Meyer and M. M. Bergman (eds), Transitions in Youth and Young Adulthood: Results from the Swiss TREE Panel Study, Vol. 2, Zürich, Switzerland: Seismo, pp. 183-207.

Felouzis, G. and S. Charmillot (2013), 'School tracking and educational inequality: A comparison of 12 educational systems in Switzerland', Comparative Education, 49 (2), 181-205.

Glauser, D. (2015), Berufsausbildung oder Allgemeinbildung? Soziale Ungleichheiten beim Übergang in die Sekundarstufe II in der Schweiz, Wiesbaden, Germany: Springer VS.

Hupka-Brunner, S., S. Sacchi and B. E. Stalder (2010), 'Social origin and access to upper secondary education in Switzerland: A comparison of company-based apprenticeship and exclusively school-based programmes', Schweizerische Zeitschrift für Soziologie, 36 (1), 11-31.

Hupka-Brunner, S., R. Samuel, E. Huber and M. M. Bergman (2011), 'Geschlechterungleichheiten im intergenerationalen Bildungstransfer in der Schweiz', in A. Hadjar (ed.), Geschlechtsspezifische Ungleichheiten, Wiesbaden, Germany: VS-Verlag, pp. 77-97.

Imdorf, C. (2005), Schulqualifikation und Berufsfindung. Wie Geschlecht und nationale Herkunft den Übergang in die Berufsbildung strukturieren, Wiesbaden, Germany: VS-Verlag für Sozialwissenschaften.

Karlson, K. B. and A. Holm (2011), 'Decomposing primary and secondary effects: A new decomposition method', Research in Stratification and Mobility, 29 (2), 22137.

Neuenschwander, M. P. and T. Malti (2009), 'Selektionsprozesse beim Übergang in die Sekundarstufe I und II', Zeitschrift für Erziehungswissenschaft, 12, 216-32.

Neuenschwander, M. P., M. Gerber, N. Frank and B. Rottermann (eds) (2012), Schule und Beruf. Wege in die Erwerbstätigkeit, Wiesbaden, Germany: VS Verlag für Sozialwissenschaften.

Samuel, R., M. M. Bergman and S. Hupka-Brunner (2014), 'Longitudinal effects of social background on educational and occupational pathways within early and strong school tracking', Longitudinal and Life Course Studies, 5 (1), 1-18.

Schumann, S. (2011), 'Leistungs- und Herkunftseffekte beim Hochschulzugang in der Schweiz', Zeitschrift für Pädagogik, 57 (2), 246-68.

Stalder, B. (2011), Das intellektuelle Anforderungsniveau beruflicher Grundbildungen in der Schweiz. Ratings der Jahre 1999-2005, Basel, Switzerland: TREE.

TREE (ed.) (2013), TREE Project Documentation 2000-2012, Basel, Switzerland: TREE. 